\title{
Bioinformatics strategy for the screening of key genes to differentiate adenomyosis from endometriosis (Review)
}

\author{
SHOGO IMANAKA, HARUKI NAKAMURA and HIROSHI KOBAYASHI
}

Department of Obstetrics and Gynecology, Nara Medical University, Kashihara, Nara 634-8522, Japan

Received September 11, 2019; Accepted October 14, 2019

DOI: $10.3892 /$ wasj.2019.25

\begin{abstract}
Adenomyosis is one of the most common gynecological diseases worldwide. Despite intense efforts to elucidate the pathogenesis, the molecular mechanisms responsible for adenomyosis are not yet fully understood. The aim of this review was to screen candidate functional networks and identify key genes to differentiate adenomyosis from endometriosis. A search was conducted between 2000 and 2018 through the English language literature (online MEDLINE PubMed database) using the key words, adenomyosis combined with endometriosis, differentially expressed genes (DEGs) and functional networks. Eligible microarray datasets were collected from the NCBI Gene Expression Omnibus (GEO) database, NCBI-GEO (http://www.ncbi.nlm.nih.gov/geo/). The mRNA and/or protein expression of adenomyosis candidate genes was confirmed by the published data (https://www. ncbi.nlm.nih.gov/pubmed). The comprehensive gene expression analysis based on the NCBI-GEO database revealed the candidate DEGs and functional networks. Among a total of 3,119 genes collected from the adenomyosis signatures, 2,845 genes $(91.2 \%)$ overlapped in the endometriosis signatures. A total of 274 DEGs were identified to be specific to adenomyotic lesions. Among these, we selected 50 genes whose expression profiles have been published in a public repository. Although the two conditions may share common pathways, a set of DEGs, including insulin-like growth factor 1 (IGF1), osteopontin (OPN), KiSS-1 metastasis suppressor (KISS1), neural cell adhesion molecule 1 (NCAM1, also known as CD56), versican (VCAN), L-selectin ligand and Annexin A2, (ANXA2), have been suggested to play a pivotal role in the pathophysiology of adenomyosis. The enriched functions and pathways of the DEGs include the process of endometrial invasion, cell survival, wound healing, scarring and fibrosis. On the whole, in this review, we present a comprehensive gene
\end{abstract}

Correspondence to: Professor Hiroshi Kobayashi, Department of Obstetrics and Gynecology, Nara Medical University, 840 Shijo-cho, Kashihara 634-8522, Nara, Japan

E-mail: hirokoba@naramed-u.ac.jp

Key words: adenomyosis, endometriosis, differentially expressed genes, microarray, bioinformatics expression analysis based on NCBI-GEO database to identify adenomyosis candidate genes. DEGs and functional networks help us to understand the molecular mechanisms underlying the pathogenesis of adenomyosis, and provide candidate targets for the diagnosis and treatment of adenomyosis.

\section{Contents}

1. Introduction

2. Search strategy, selection criteria and data collection

3. Differentially expressed genes and their functions between adenomyosis and endometriosis

4. Conclusions and future considerations

5. Summary

\section{Introduction}

Adenomyosis is a benign uterine condition characterized by the presence of ectopic endometrial glands and stroma in the myometrium and muscular hypertrophy/hyperplasia associated with increased vascularity and reactive fibrosis (1). According to the most convincing theory, adenomyosis was originally thought to originate from the invagination of the basalis of the endometrium into the inner myometrium $(1,2)$. In addition, this disorder may possibly result from metaplastic alterations of Müllerian duct remnants. Adenomyosis is a clinical condition with a high association of endometriosis and vice versa, with a marked prevalence in women of reproductive age (3). Emerging evidence has indicated that this disorder appears to consist of heterogeneous subtypes with different causes and etiologies (4). Certain adenomyosis populations occur in the uterine outer layer without affecting the inner myometrial structures (4). A number of various pathogenetic theories have described the mechanisms through which adenomyosis develops; however, the origin of adenomyosis remains unclear (1).

On the other hand, endometriosis is a common benign disease caused by the presence of endometrial tissue outside the uterine cavity or in ectopic locations, e.g., peritoneal implants, ovarian cysts and deep infiltrating nodules (5). There are a number of hypotheses regarding the complex etiology of endometriosis: Retrograde menstruation, coelomic metaplasia and Müllerian duct remnants; however, none have been postulated to completely explain the etiology of endometriosis (5). 
Several researchers have performed a large-scale survey for the identification of differentially expressed genes (DEGs) between the eutopic and ectopic endometrium of women with endometriosis (6-11). Some studies have examined the global transcriptome of isolated ectopic and eutopic tissues from women with adenomyosis (12-14). However, to date, to the best of our knowledge, there is no clear evidence to indicate that fundamental differences exist in the underlying mechanisms of disease development between adenomyosis and endometriosis. Therefore, in this review, multiple independent microarray datasets that are available through an open access, comprehensive database, were utilized to identify reliable adenomyosis-specific pathways and DEGs. The expression levels of adenomyosis candidate genes were confirmed by the data published in a peer-reviewed journal. The aim of this review was to summarize the studies available to date on candidate key genes and functional networks involved in the differentiation between adenomyosis and endometriosis.

\section{Search strategy, selection criteria and data collection}

A review of the literature was conducted in order to screen candidate key genes and functional networks that differentiate adenomyosis from endometriosis. A MEDLINE search was performed using the key words 'adenomyosis', 'endometriosis', 'differentially expressed genes' and 'functional networks'. English language publications in PubMed and references from relevant articles published between January, 2000 and December, 2018 were analyzed. There were 17 articles available for 'differentially expressed genes' AND 'functional networks' AND 'endometriosis', and 1 article available for 'differentially expressed genes' AND 'functional networks' AND 'adenomyosis' by search. References in the studies identified were also searched. In addition, the development of bioinformatics methods, including DNA microarray and RNA-Seq technologies, could provide a better understanding of the pathogenetic events of the development of adenomyosis and endometriosis at the genome level. These data have been made available through an open access, comprehensive PubMed database that compiles up-to-date omics technologies regarding human adenomyosis and endometriosis. Eligible archives for functional genomics microarray datasets were collected from the National Center for Biotechnology Information (NCBI)-Gene Expression Omnibus (GEO) database, NCBI-GEO (http://www.ncbi.nlm.nih.gov/geo/). GEO dataset searches up to December, 2018, using keywords 'adenomyosis' and 'endometriosis' and the accession number of meta-data tag. 47 articles were available in the GEO database for endometriosis and adenomyosis by search. The inclusion criteria included the following: i) Original genomic studies that screened for DEGs among adenomyosis, endometriosis, or healthy individuals; ii) array analysis studies of gene expression profiling; and iii) studies comprised of raw files. The following data can be accessed via key word search: 'Adenomyosis AND ectopic AND human' [n=4, GEO accession nos. GSE68870 (14), GSE74373 (12), GSE78851 (13) and GSE7307]; and 'endometriosis AND ectopic AND human' [n=12, GEO accession nos. GSE68870 (14), GSE7307, GSE25628 (6), GSE40186 (7), GSE47359 (11), GSE51981 (8), GSE73948 (9), GSE94414, GSE99949, GSE105764 (10),
GSE105765 (10) and GSE124010] (Table I). Fourteen publications available in the GEO database were selected based on the final selection taking into account the experiment type, overall design and microarray platforms. The flow chart of the literature search are presented in Fig. 1.

\section{Differentially expressed genes and their functions between adenomyosis and endometriosis}

We combined the data derived from GEO, analyzed the similarities and differences between ectopic tissue samples from patients with adenomyosis and those from patients with endometriosis, and then focused on the unequivocal identification of the adenomyosis related genes. The DEGs between adenomyosis samples and endometriosis samples were screened using GEO2R (http://www.ncbi.nlm.nih.gov/geo/geo2r). Probe sets without corresponding gene symbols were removed. Following pre-processing, DEGs with $\log 2$ fold change $>2$ or $<1 / 2$, a false discovery rate $<0.05$ and P-value $<0.01$ were selected as described previously (15). Functional annotation and gene regulatory networks were performed based on the Gene Ontology (GO) database (https://david.ncifcrf.gov/tools.jsp). The expression of adenomyosis candidate genes were confirmed by the data published in a peer-reviewed journal (https://www.ncbi. nlm.nih.gov/pubmed and https://www.ncbi.nlm.nih.gov/gene).

Screening of key genes with which to differentiate adenomyosis from endometriosis. In this section, the gene expression features and core regulatory genes which can be used to differentiate adenomyosis from endometriosis by using high-throughput microarray genomics datasets downloaded from the NCBI-GEO database are discussed. The GEO database for adenomyosis [ $\mathrm{n}=4$, GEO accession nos. GSE68870 (14), GSE74373 (12), GSE78851 (13) and GSE7307] and GEO database for endometriosis [ $\mathrm{n}=12$, GEO accession nos. GSE68870 (14), GSE7307, GSE25628 (6), GSE40186 (7), GSE47359 (11), GSE51981 (8), GSE73948 (9), GSE94414, GSE99949, GSE105764 (10), GSE105765 (10) and GSE124010)] enabled us to screen DEGs between the two conditions. Among these databases, we selected the gene expression profiles of GSE68870 (14), GSE78851 (13) and GSE7307 for adenomyosis and GSE68870 (14), GSE7307 and GSE25628 (6) for endometriosis, particularly when taking their experiment type, overall design and platforms into consideration (Table I).

To reveal the differences in gene expression between the adenomyosis and endometriosis tissues, the top ranked genes with a $\log 2$ fold change $>2$ or $\log 2$ fold change $<1 / 2$ were selected for analysis. Among a total of 3,119 genes collected from the adenomyosis signatures, 2,845 genes (91.2\%) overlapped in the endometriosis signatures. This suggests that patients with adenomyosis and endometriosis share a common genetic pathophysiology. On the other hand, a total of 274 DEGs were identified to be specific to ectopic lesions of patients with adenomyosis. Among these adenomyosis candidate genes, we selected 50 genes (18.2\%) whose expression profiles have been published in a public repository, PubMed database (https://www.ncbi.nlm.nih. gov/pubmed/) (Table II). In comparison with the genetic and proteomic data previously published for adenomyosis and 


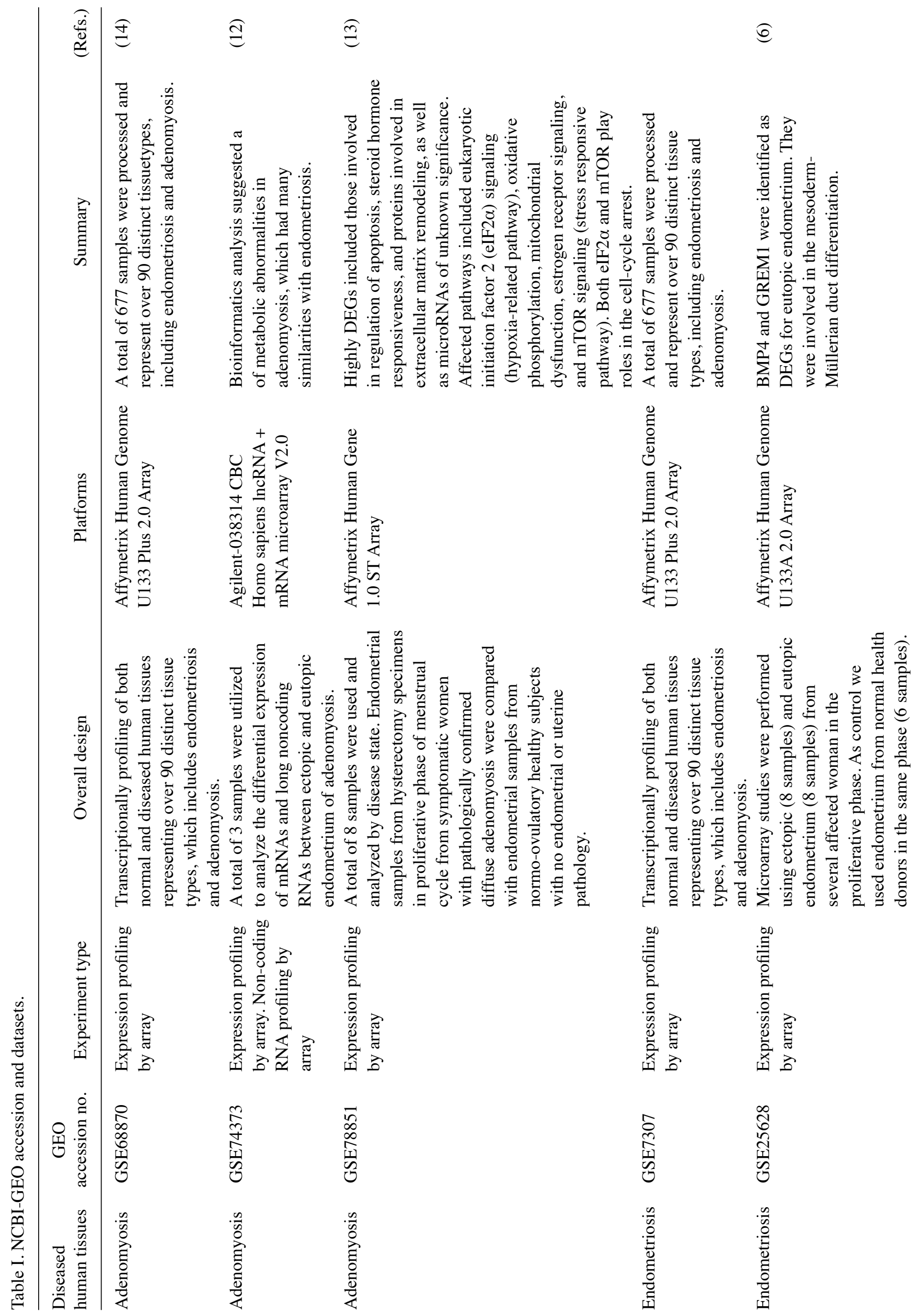




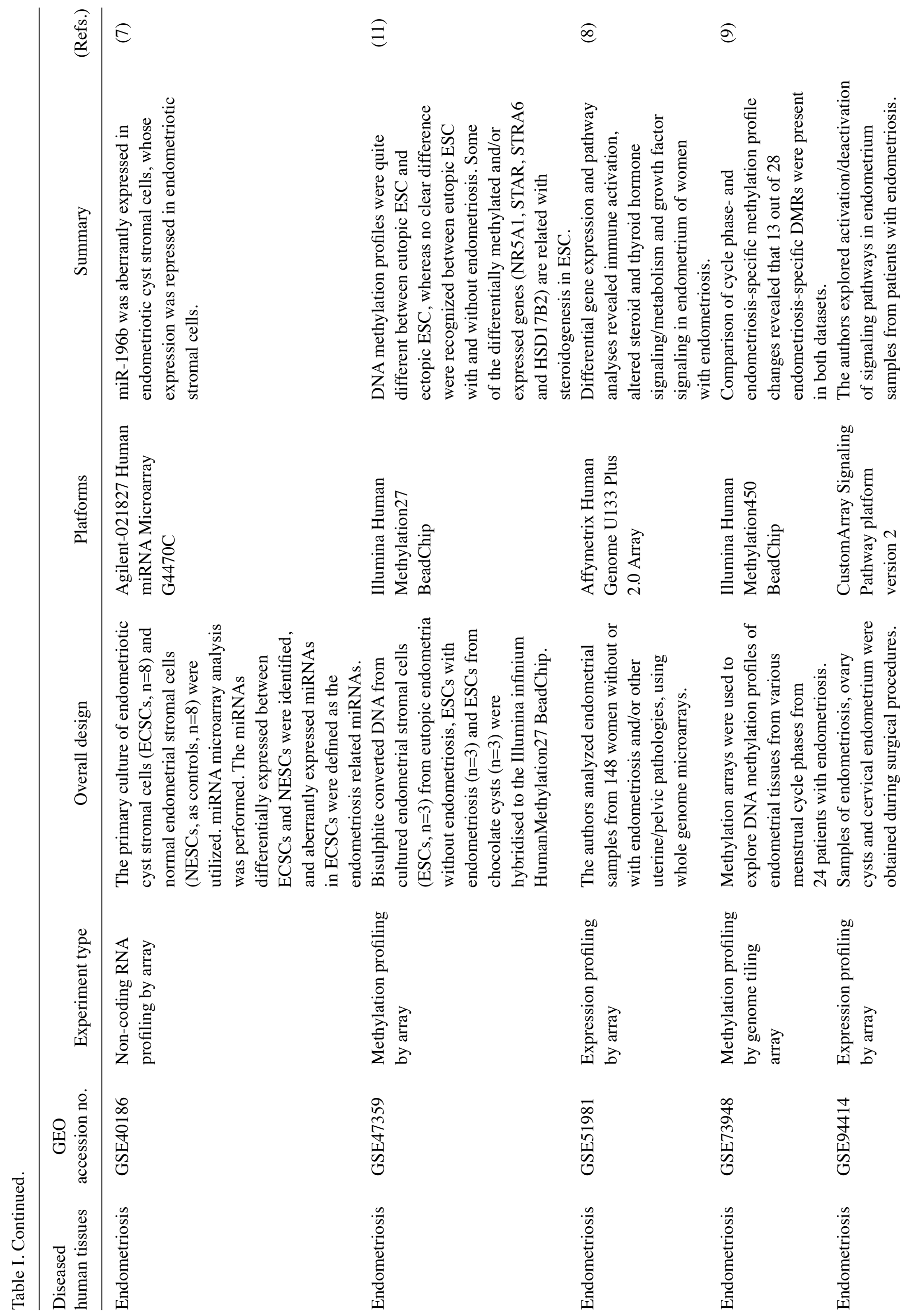




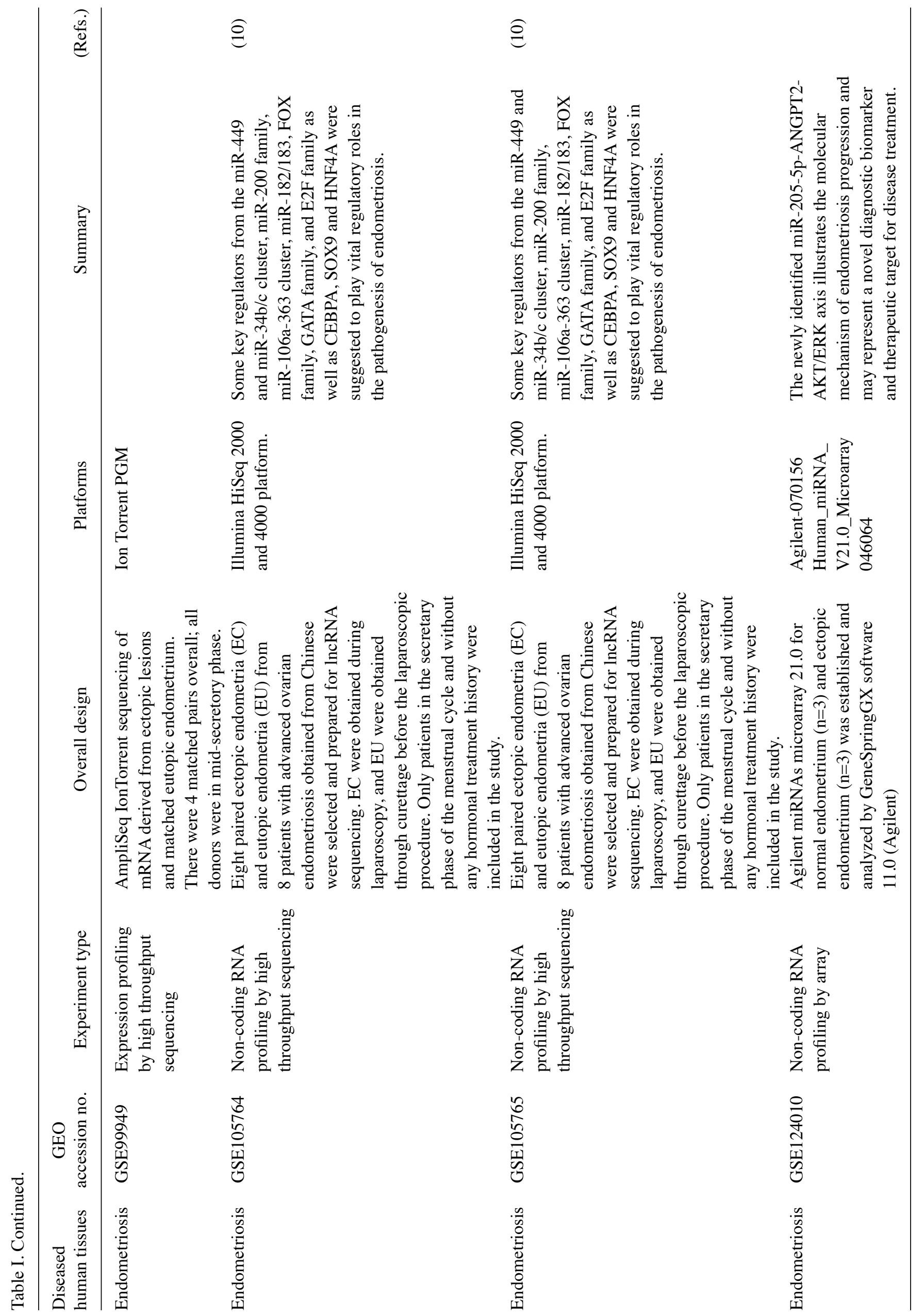




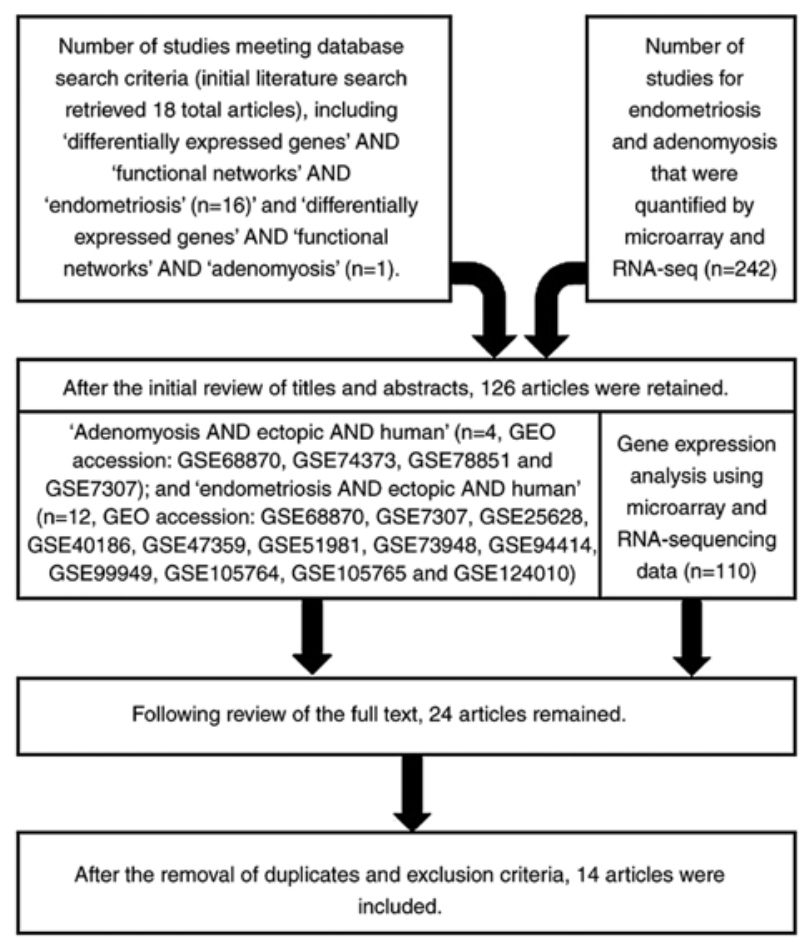

Figure 1. Study selection for a comprehensive literature search. This figure shows the flow chart of the literature search.

endometriosis, a set of DEGs, including insulin-like growth factor 1 (IGF1) (16-19), osteopontin (OPN) (20-22), KiSS-1 metastasis suppressor (KISS1) (23-27), neural cell adhesion molecule 1 (NCAM1, also known as CD56) $(28,29)$, versican (VCAN) (13,30), L-selectin ligand (31) and Annexin A2 (ANXA2) (32-35), were considered to be target genes for adenomyosis. These previous studies revealed that, among these, 4 genes (IGF1, KISS1, NCAM1 and ANXA2) were upregulated, and 3 genes (OPN, VCAN and L-selectin ligand) were downregulated.

Functional pathways of adenomyosis candidate genes. GO term enrichment analysis suggested that DEGs were significantly enriched in survival and apoptosis, immune and inflammatory response, invasion and extracellular matrix remodeling, adhesion, hormonal response, epithelial-mesenchymal transition, cell cycle regulation, angiogenesis, oxidative damage, mitochondrial dysfunction and prostaglandin biosynthesis (Table II). Taken together with the DEGs, the enriched functions and pathway analysis revealed that the adenomyosis candidate genes may be the core regulatory functions and may play pivotal roles in the processes of invasion of the endometrial basalis into the myometrium (KISS1), avoidance of the immune attack (OPN), cell survival (IGF1), wound repair, healing and scarring (NCAM1) and fibrosis (ANXA2). The biological functions of adenomyosis candidate genes in implicating disease pathways were comprehensively searched using the PubMed database.

Survival and apoptosis (13 genes). Adenomyosis is involved in eutopic endometrial invagination/infiltration into the inner myometrium by modulating the proliferative, invasive and angiogenic responses, which is a hallmark of adenomyosis (13). Increased proliferation and decreased apoptosis may be critical for the pathophysiology of adenomyosis and endometriosis; however, the underlying regulatory mechanisms remain elusive (36). In adenomyosis, $\mathrm{Ki}-67$ is expressed in the glandular epithelium of the ectopic endometrium and myometrial cells associated with hyperplasia and hypertrophy, irrespective of the menstrual phases (36-38). The genes and pathways involved in the regulation of apoptosis have been shown to be aberrantly expressed in the endometrium of women with adenomyosis, compared to the controls (39). We found that the survival and apoptosis-related genes were upregulated or downregulated in the previous studies cited. Thus, the proliferation- and growth-related genes, including IGF1 (16-19), IGF2 (19), vascular endothelial growth factor (VEGF) (40-42), hepatocyte growth factor (HGF) (43-45), nerve growth factor (NGF) (46-48), platelet-derived growth factor (PDGF) $(16,49)$, epidermal growth factor receptor (EGFR) $(16,17,49,50)$, fibroblast growth factor 2 (FGF2) $(49,51,52)$ and mechanistic target of rapamycin kinase (mTOR) $(53,54)$, were upregulated in both the ectopic and eutopic endometria from subjects with adenomyosis compared with the eutopic endometria from women without adenomyosis, while the anti-apoptotic or autophagy-related genes, such as BCL2 apoptosis regulator (BCL2) $(38,55-57)$, beclin 1 (BECN1) $(58,59)$ and programmed cell death 4 (PDCD4) $(60,61)$, were much higher in the ectopic and eutopic endometria than in the control endometria. Furthermore, the decreased expression of BCL2 associated $\mathrm{X}$, apoptosis regulator (BAX) has been observed in adenomyosis, suggesting that the downregulation of apoptotic cell death machinery is a hallmark of adenomyosis (39). Among these genes, IGF1 was identified as one of the candidate key regulators to differentiate adenomyosis from endometriosis.

i) IGF1. IGF1 may influence the growth and survival of the endometrium by regulating its receptor IGF1R signaling pathway. The immunohistochemical protein expression of IGF1 and IGF1R has been shown to be upregulated in adenomyosis foci and the myometrium in the proliferative phase than in the secretory phase $(16,17)$. It has been demonstrated that the overexpression of IGF1R mRNA and protein is not altered throughout the menstrual cycle in the eutopic endometrium of patients with adenomyosis (17). On the other hand, the protein expression of IGF1 and IGF1R has been shown to be similar between ectopic and eutopic endometrial tissues of patients with endometriosis throughout the cycle (18). The IGF1 levels in peritoneal fluid have been shown to be higher in patients with endometriosis than in control subjects, although the data remain controversial (19). Therefore, the IGF1 levels are significantly higher in adenomyosis cases compared to endometriosis cases. As previously demonstrated, the IGF2 levels did not differ between the two diseases (19).

The expression levels of the 'survival and apoptosis' related genes, including BAX, BCL2, IGF2, VEGF, HGF, NGF, PDGF, EGFR, FGF2, MTOR, BECN1 and PDCD4, were similar between the two diseases.

ii) BCL2. In general, ectopic cells of adenomyosis and endometriosis can block apoptotic cell death, which is regulated by the anti-apoptotic factor BCL2 family and caspase family of proteins. BCL2 is upregulated in adenomyosis during the proliferative phase, reaching a peak during 
Table II. Functional classification of differentially expressed genes in adenomyosis and endometriosis.

\begin{tabular}{|c|c|c|c|c|}
\hline \multirow[b]{2}{*}{ The major pathways } & \multicolumn{3}{|c|}{ Differentially expressed genes } & \multirow[b]{2}{*}{ (Refs.) } \\
\hline & $\mathrm{ADM}>\mathrm{END}^{\mathrm{a}}$ & $\mathrm{ADM}<\mathrm{END}^{\mathrm{b}}$ & $\mathrm{ADM}=\mathrm{END}$ & \\
\hline \multirow[t]{13}{*}{ Survival and apoptosis $(n=13)$} & IGF1 & & & $(16-19)$ \\
\hline & & & BAX & (39) \\
\hline & & & BCL2 & $(38,55-57)$ \\
\hline & & & IGF2 & (19) \\
\hline & & & VEGF & $(40-42)$ \\
\hline & & & HGF & $(43-45)$ \\
\hline & & & NGF & $(46-48)$ \\
\hline & & & PDGF & $(16,49)$ \\
\hline & & & EGFR & $(16,17,49,50)$ \\
\hline & & & FGF2 & $(49,51,52)$ \\
\hline & & & mTOR & $(53,54)$ \\
\hline & & & BECN1 & $(58,59)$ \\
\hline & & & PDCD4 & $(60,61)$ \\
\hline \multirow[t]{12}{*}{ Immune and inflammatory response $(n=12)$} & & OPN & & $(20-22)$ \\
\hline & & & KIR3DL1, KIR2DL3 & $(63,64)$ \\
\hline & & & GM-CSF & $(65,66)$ \\
\hline & & & $\mathrm{NF}-\kappa \mathrm{B}$ & $(67)$ \\
\hline & & & TGF- $\beta$ & $(68-71)$ \\
\hline & & & LIF & $(72,73)$ \\
\hline & & & TLR4 & $(74,75)$ \\
\hline & & & IL- $1 \beta$ & $(46,76)$ \\
\hline & & & IL-10 & $(77,78)$ \\
\hline & & & CXCL1 & $(40,79,80)$ \\
\hline & & & TrkB & $(81,82)$ \\
\hline & & & $\mathrm{COX}-2$ & $(83-86)$ \\
\hline \multirow[t]{5}{*}{ Invasion and extracellular matrix remodeling $(n=5)$} & KISS1 & & & $(23-27)$ \\
\hline & & & MMP-2, -9 & $(83,87-89)$ \\
\hline & & & MSN & $(90,91)$ \\
\hline & & & FAK & $(92,93)$ \\
\hline & & & LOX & $(68,94)$ \\
\hline \multirow[t]{5}{*}{ Adhesion $(n=5)$} & NCAM1 & & & $(28,29)$ \\
\hline & & VCAN & & $(13,30)$ \\
\hline & & L-selectin ligand & & $(31)$ \\
\hline & & & SRGAP2 & $(96,97)$ \\
\hline & & & ADAM12 & $(96,98,99)$ \\
\hline \multirow[t]{5}{*}{ Hormonal response $(n=5)$} & & & ESR1 & $(37,67,102,103)$ \\
\hline & & & ESR2 & $(37,67,102,103)$ \\
\hline & & & PR-B & $(67,102,103)$ \\
\hline & & & $\mathrm{RXR} \alpha$ & $(16,104)$ \\
\hline & & & OXTR & $(105-107)$ \\
\hline \multirow[t]{3}{*}{ Epithelial-mesenchymal transition $(n=3)$} & ANXA2 & & & $(32-35)$ \\
\hline & & & ILK & $(111-113)$ \\
\hline & & & CTNNB1 & $(45,114-117)$ \\
\hline \multirow[t]{3}{*}{ Cell cycle regulation $(n=3)$} & & & MSI1 & $(119,120)$ \\
\hline & & & SOX2 & $(121)$ \\
\hline & & & 4-Oct & $(121)$ \\
\hline Angiogenesis $(n=1)$ & & & $\mathrm{HIF}-1 \alpha$ & $(41,123)$ \\
\hline Oxidative damage $(n=1)$ & & & GPX & $(13,125)$ \\
\hline Mitochondrial dysfunction $(n=1)$ & & & SOD2 & $(127,128)$ \\
\hline Prostaglandin biosynthesis $(n=1)$ & & & PTGS2 & $(83-86)$ \\
\hline
\end{tabular}

A search in the PubMed repository to collect information about the expression of target genes and proteins was carried out. ${ }^{\mathrm{a}} \mathrm{Gene}$ and protein expression is increased in the ectopic endometrium of patients with adenomyosis compared to that of patients with endometriosis. ${ }^{\mathrm{b}} \mathrm{Gene}$ and protein expression is increased in the ectopic endometrium of patients with endometriosis compared to that of patients with adenomyosis. ADM, adenomyosis; END, endometriosis. 
ovulation to decrease to values close to zero in the late luteal phase $(57,62)$. BCL2 is also overexpressed in endometrial stromal cells of patients with adenomyosis (57). Furthermore, the expression of BCL2 has been shown to be increased in endometriotic stromal cells compared to the paired eutopic cells (38). BCL2 is persistently overexpressed during both proliferative and luteal phases of the cycle in ovarian endometriotic tissues (55).

iii) $B A X$. Bax protein forms a heterodimer with $\mathrm{Bcl}-2$, and functions as an apoptotic activator. The protein expression of Bax has been shown to be decreased in the eutopic endometrium from endometriosis compared with the control (39). No significant differences in BAX expression have been between endometriosis and adenomyosis (55).

iv) VEGF. Angiogenesis and neovascularization are considered to be the major pathological features of adenomyosis and endometriosis (42). VEGF expression has been shown to be increased in the eutopic endometrium in patients with adenomyosis compared to women without adenomyosis $(40,41)$. In adenomyosis, $17 \beta$-estradiol (E2) has been shown to induce pro-angiogenic activity in vascular endothelial cells through the snail family transcriptional repressor 2 (SNAI2)-VEGF axis (42).

v) $H G F$. HGF may contribute to endometrial cell invagination deep into the myometrium at the endo-myometrial junction in women with adenomyosis through the epithelial-mesenchymal transition (EMT) pathway (43). The upregulation of HGF, VEGFR2, hypoxia inducible factor 1 subunit $\alpha$ (HIF-1 $\alpha$ ), PDGFB, neuropilin 1 (NRP1) and EPH receptor B4 (EPHB4) has been identified in the ectopic and eutopic endometrium of women with endometriosis compared to that of the controls $(44,45)$.

vi) $N G F$. NGF mRNA expression has been shown to be increased in the ectopic endometrium of patients with adenomyosis (46) or endometriosis (48) compared to the eutopic endometrium or normal endometrium. E2 promotes NGF production in adenomyosis endometrial stromal cells, but not in control endometrial stromal cells (47).

vii) PDGF. The expression level of PDGF has been shown to be decreased in adenomyosis (16) and endometriosis (49) compared with the control.

viii) EGFR. EGFR is downregulated in the adenomyotic (16) and endometriotic (50) tissues compared to that in the normal endometrial tissues.

ix) FGF2. FGF2 has been shown to be upregulated in adenomyosis (51) and endometriosis (49) compared to healthy controls, which may contribute to the proliferation of ectopic cells through the FGF2/Extracellular signal-regulated kinase (ERK) $1 / 2$ signaling pathway (52).

x) MTOR. Endometrial cells proliferate, migrate and survive by modulating the phosphatidylinositol 3-kinase (PI3K)/AKT/p-mTOR signaling pathway (53). The expression of p-mTOR has been shown to be higher in the ectopic endometrium than in the eutopic endometrium of patients with endometriosis or adenomyosis $(53,54)$.

xi) BECN1. BECN1 is an autophagy-related gene (58). The expression of Beclin $1 \mathrm{mRNA}$ and protein has been shown to be decreased in both ectopic and eutopic endometriotic tissues from women with adenomyosis (58) or endometriosis (59) compared with endometrium from healthy women, suggesting that autophagy hisrelated to the pathogenesis and progression of the two conditions.

xii) PDCD4. PDCD4 is involved in the apoptotic pathway and is a tumor suppressor gene, which is downregulated in adenomyosis (60) and endometriosis (61) possibly through the nuclear factor (NF)- $\mathrm{kB} /$ mammalian target of rapamycin (MMP)2/MMP9 signaling pathway.

Immune and inflammatory response (12 genes). The alterations to the immune response and inflammation in the surrounding microenvironment may play a role at different stages of adenomyosis and endometriosis development, including initiation, invasion, promotion, survival and progression. The pathway involved in 'Immune and inflammatory response' includes OPN, killer cell immunoglobulin-like receptors (KIRs; KIR3DL1 and KIR2DL3), granulocyte-macrophage colony-stimulating factor (GM-CSF), $\mathrm{NF}-\kappa \mathrm{B}$, transforming growth factor- $\beta$ (TGF- $\beta$ ), leukemia inhibitory factor (LIF), Toll-like receptor (TLR), interleukin (IL)-1 $\beta$, IL-10, C-X-C motif chemokine ligand 1 (CXCL1), tropomycin receptor kinase B (TrkB) and cyclooxygenase-2 $(\mathrm{COX}-2)$.

i) $O P N$. OPN is a multifunctional cytokine and upregulates the expression of interferon- $\gamma$ (IFN- $\gamma$ ) and IL-12. IFN- $\gamma$, one of the immunostimulatory cytokines, activates natural killer (NK) cell cytotoxicity. IL-12, a pleiotropic cytokine, also plays an essential role in the activation of both innate (NK cells) and adaptive (cytotoxic T lymphocytes) immunities. Higher OPN mRNA and protein levels have been observed in both the ectopic and eutopic endometrium from subjects with endometriosis compared with the endometrium from women without endometriosis (22). Conversely, the expression levels of OPN mRNA and protein have been shown to be lower in patients with adenomyosis than in the controls $(20,21)$. The altered expression of OPN programs an immune environment that may be obligatory for adenomyosis progression.

No significant difference in the expression levels of the following genes was noted in adenomyosis and in endometriosis: NK cell markers (KIR3DL1, KIR2DL3), GM-CSF, NF- $\kappa$ B, TGF- $\beta$, LIF, TLR, IL-1 $\beta$, IL-10, CXCL1, TrkB and COX-2.

ii) KIR. NK cells contribute to early defense against infected cells and tumor cells. NK cells have a decreased expression of inhibitory KIRs, including KIR3DL1 (also known as NKB1) and KIR2DL3 (also known as GL183), on their surface and have enhanced cytotoxic functions. In endometriosis, peripheral NK cells and peritoneal NK cells exhibit an increased expression of KIRs and have reduced levels of cytotoxicity (63). Endometriotic cells develop several strategies to escape immune surveillance to avoid attack from the immune system. Ectopic lesions of adenomyosis have an increased expression of KIRs (64). By contrast, the expression of inhibitory KIRs is decreased in the eutopic endometrium, but not in the ectopic lesion, in women with adenomyosis, demonstrating a greater cytotoxic activity (64).

iii) GM-CSF. GM-CSF is highly expressed in the ectopic compared with the eutopic tissue in patients with endometriosis (65), as well as in patients with adenomyosis (66). GM-CSF-activated phagocytes cause tissue damage during inflammation. 
iv) $N F-\kappa B . N F-\kappa B$ is a critical pro-inflammatory regulator that has been suggested to play a pivotal role in the expression of proinflammatory genes, including cytokines, chemokines and adhesion molecules (67). NF- $\kappa \mathrm{B}$ is considered to play a central role in the pathogenesis of endometriosis and adenomyosis (67).

v) $T G F-\beta$. The ectopic endometrium of women with adenomyosis and endometriosis exhibits an increased expression of TGF- $\beta 1$ and phosphorylated SMAD family member 3 (Smad3), markers of EMT, and increased fibrosis as compared with the normal endometrium $(68,69)$. TGF- $\beta 1 / \mathrm{Smad} 3$ and IL-6/Janus kinase 2 (JAK2)/signal transducer and activator of transcription 3 (STAT3) signaling pathways are upregulated in adenomyosis (70). TGF- $\beta$ is increased in the serum, peritoneal fluid, ectopic endometrium and peritoneum of women with endometriosis compared to women without endometriosis (71).

vi) $L I F$. LIF has biological actions in maternal receptivity to blastocyst implantation, embryo implantation and placental formation, possibly through the activation of STAT3 and ERK signaling (72). Adenomyosis and endometriosis have negative impacts on embryo implantation. Patients with adenomyosis (72) or endometriosis (73) exhibit a decreased expression of LIF and its receptor, LIFR, in the eutopic endometrium as compared with healthy women.

vii) TLR4. The expression of TLRs (TLR1, 2, 4, 5 and 9) is higher in the ectopic endometrium and eutopic endometrium in adenomyosis as compared with the normal endometrium, and positively correlates with IL-6 and IL-8 (74). Similar to adenomyosis, TLR4 is overexpressed in endometriosis, indicating that both conditions are a state of inflammatory pathology (75).

viii) $I L-1 \beta$. The overexpression of IL-1 $\beta$ has been identified in adenomyosis (46) and endometriosis (76), which is linked with an ability to transform acute inflammation to the chronic inflammation.

ix) $I L-10$. The anti-inflammatory cytokine, IL-10, may play critical roles in suppressing immunity against embryo implantation (77). IL-10 protein is overexpressed in the ectopic and eutopic endometrium of women with adenomyosis compared to the normal endometrium (78). The serum level of IL-10 in patients with endometriosis is also higher than that in healthy subjects (77).

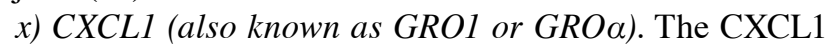
chemokine is a secreted growth factor that signals through the G-protein coupled receptor, $\mathrm{CXC}$ receptor 2, and acts as a neutrophil-activating factor. CXCL1 is overexpressed in the epithelium of the endometrium in adenomyosis (40) and endometriosis $(79,80)$. VEGF contributes to the production of CXCL1 in endometrial epithelial cells through the $\mathrm{NF}-\kappa \mathrm{B}$ signaling pathway (40). IL-17A also induces CXCL1 expression (80).

xi) $\operatorname{TrkB}$. TrkB is a receptor for the main neurotrophins (NGF and BDNF) and detected in endometriosis tissue. TrkB is expressed in te eutopic endometrium of proliferative phase of women with endometriosis (81), while its expression has been detected in the secretory endometrium of women with adenomyosis (82). TrkB has not been found in the endometrium of the proliferative or secretory phase in the control group (81).

xii) $C O X-2$ [also known as prostaglandin-endoperoxide synthase 2 (PTGS2)]. COX-2 is responsible for the prostaglandin biosynthesis involved in inflammation. Several studies have demonstrated the overexpression of COX-2 in adenomyosis $(83,84)$ and endometriosis, particularly in the endometriotic ovarian cyst wall $(85,86)$. IL- $1 \beta$ induces the expression of COX-2 and VEGF through the MAPK/ERK signaling pathway (86).

Invasion and extracellular matrix remodeling (5 genes). The eutopic endometrium of women with adenomyosis exhibits multiple pathways that predispose to the endometrial infiltration and invasion (13). ECM degradation and remodeling may be the cause of eutopic and ectopic endometrial invasion in adenomyosis and endometriosis. Below, key DEGs that promote adenomyotic and endometriotic cell migration and invasion are discussed.

i) KISS1. KISS1 was initially found to function as a metastasis suppressor and also involved in endocrine functions, glucose homeostasis and insulin secretion (26). KISS1 suppresses the metastases of melanomas, colon cancer and breast cancer through inhibiting cell-matrix adhesion, cytoskeletal reorganization, chemotaxis and invasion (24). KISS1 prevents the growth and colonization of metastatic cells in distant sites and delays the metastatic cascade. KISS1 exerts multiple effects on cancer cell biology through a G-protein-coupled receptor, GPR54. The expression of KISS1 is upregulated in adenomyosis (23), but not in endometriosis (25). Thus, the question may be raised as to whether and how KISS1 is involved in the pathogenesis of adenomyosis. The existing data are controversial. Fratangelo et al reported that KISS1 plays a role in the early steps of breast cancer development (27).

Although MMP-2, MMP-9, moesin (MSN), focal adhesion kinase (FAK) and lysyl oxidase (LOX) are overexpressed in the ectopic endometrium of women with adenomyosis and endometriosis, the expression levels of these genes have been found to be similar between the two conditions.

ii) $M M P$. The increased expression of MMP-2 and -9 in the eutopic endometrium may play a role in the development of adenomyosis $(83,87)$ and endometriosis $(88)$. The MMP-7-181A/G polymorphism may be associated with the susceptibility to adenomyosis and endometriosis (89).

iii) MSN. MSN is a member of the ezrin, radixin and moesin (ERM) protein family that participates in the key events of the carcinogenesis processes, such as cellular morphology, adhesion, migration and tumor invasion through a cross-linking between membrane proteins and the actin-based cytoskeleton. MSN mRNA and protein expression levels have been shown to be upregulated in adenomyosis (90). In addition, MSN is overexpressed and produced in ovarian endometrioma (91).

iv) FAK. FAK is a cytoplasmic protein tyrosine kinase that is overexpressed and activated in several types of cancer (92). FAK promotes cell motility, survival and proliferation through the EMT process and the PI3K/AKT signaling pathway (92). FAK expression is increased in adenomyosis (92) and endometriosis (93). FAK may play a role in the pathogenesis of the two conditions.

v) $L O X$. LOX is an enzyme involved in collagen deposition, extracellular membrane remodeling and invasive potential. LOX exressionis increased in adenomyosis (68) and endometriosis (94). The aberrant expression of LOX destabilizes the ECM, resulting in ECM degradation and remodeling. 
Adhesion (5 genes). The adhesion and migration of endometrial cells are required to establish adenomyotic lesions within the myometrium. The levels of adhesion-related genes, neural cell adhesion molecule 1 (NCAM1), versican (VCAN), L-selectin ligand, SLIT-ROBO Rho GTPase activating protein 2 (SRGAP2) and disintegrin and metalloproteinase domain-containing protein 12 (ADAM12), are altered in both the ectopic and eutopic endometrium from patients with adenomyosis compared with the eutopic endometrium from women without adenomyosis. Among these, NCAM1 is upregulated and VCAN and L-selectin ligand are downregulated in the ectopic endometrium in adenomyosis than in the corresponding eutopic endometrium and control groups. A adenomyotic cell-induced switch of attachment into detachment may, in turn, trigger a range of cell invasive signals accompanied by destruction of ECM, thus creating an optimal niche for adenomyotic cells to grow.

i) NCAM1 (also known as CD56). NCAM1, also known as CD56, is a NK cell marker and is involved in cell-to-cell interactions, as well as cell-matrix interactions. NCAM1 expression has been shown to be increased in the ectopic endometrium of patients with adenomyosis (28), while a decreased NCAM1 expression has been observed in the ectopic endometrium of patients with endometriosis (29). Muscle repair and scarring are driven by migratory $\mathrm{CD}^{+} 6^{+} \mathrm{NK}$ cells, macrophages and fibroblasts that infiltrate injury sites and secrete growth factors (95). This suggests that adenomyosis-related wound healing and scarring may be associated with an increased $\mathrm{CD}^{+} 6^{+}$cell infiltrate. Therefore, an increased NCAM1 expression may be associated with the severity of dysmenorrhea (28).

ii) VCAN, versican. VCAN, a major component of the ECM, is a large chondroitin sulfate proteoglycan. This gene plays a central role in tissue morphogenesis and maintenance through cell adhesion, migration, proliferation and angiogenesis. VCAN is one of the molecules upregulated in endometriosis (30), while this protein is downregulated in adenomyosis (13).

iii) L-selectin ligand. The selectins mediate inflammatory leukocyte trafficking on vascular endothelial cell surfaces, which transduces the intracellular signal transduction processes through selectin ligands. L-selectins induce the integrin $\beta 2$-dependent tyrosine phosphorylation of multiple proteins, resulting in the enhancement of target cell adhesion, slow rolling and recruitment. The expression of L-selectin ligands is increased in endometriosis, but decreased in adenomyosis (31). Aberrant adhesion represents an acquired advantage of tumor cells directly responsible for an invasive phenotype, which is considered to be a hallmark of cancer progression. A reduced expression of adhesion molecules may contribute to an enhanced invasive phenotype of adenomyotic cells. However, constitutive defects in L-selectin ligand expression may be attributed to poor uterine receptivity and cause implantation failure (31). Future studies are required to focus on the mechanisms through which L-selectin ligands affect adenomyotic cell adhesion, migration and invasion.

iv) SRGAP2. SLITs stimulates the GTPase activity of RAC1 through the transmembrane receptor roundabout (ROBO). SLIT/ROBO signaling has been linked to roles in neuronal migration, leukocyte chemotaxis, angiogenesis and cancer progression (96). The microvascular density is associated with SLIT expression (96). SRGAP2 increases cell adhesion spreading and decreases cell migration. SLIT/ROBO expression is higher in the ectopic endometrium from women with adenomyosis (97) and endometriosis (96) compared with the normal endometrium. SLIT/ROBO expression is higher in recurrent endometriosis cases than in non-recurrent cases (96).

v) ADAM12. ADAM12 has been shown to be involved in the regulation of a variety of biological processes, including fertilization, muscle development, neurogenesis and tumor angiogenesis. ADAM12 facilitates tumor angiogenesis through the activation of EGFR/STAT3/AKT-dependent pathways (98). Similar to adenomyosis, ADAM12 levels are upregulated in endometriosis that has undergone a switch to the angiogenic phenotype (96). ADAM12 is involved in heparin binding EGF-like growth factor (HB-EGF) shedding in endometriosis (99).

Hormonal response (5 genes). Estrogen receptor (ER) may be an important regulator in controlling gene expression in endometriosis and may contribute to disease formation, establishment, maintenance and progression (100). Functional downstream target genes of ER may contribute to the epigenetic susceptibility to endometriosis (100). An enhanced $\mathrm{ER} \beta$ (ESR2) activity stimulates the progression of endometriosis by inhibiting tumor necrosis factor- $\alpha$ (TNF- $\alpha$ )-induced apoptosis and increasing IL- $1 \beta$-dependent cellular adhesion and proliferation (101). The steroid hormone-mediated decidualization signaling pathway is considered to be dysregulated in endometriosis (100). Progesterone resistance is associated with endometriosis and contributes to impaired decidualization. The expression levels of ESR2, progesterone receptor isoform $\mathrm{B}$ (PR-B), retinoid X receptor $\alpha(\mathrm{RXR} \alpha)$ and oxytocin receptor (OXTR) genes and/or proteins are dysregulated in the ectopic endometrial tissues of women with adenomyosis and endometriosis. We could not find any key genes that can differentiate adenomyosis from endometriosis.

i) Estrogen receptor 1 (ESR1;ER $\alpha)$; ii) $E S R 2$ (ER $\beta)$; and iii) progesterone receptor isoform $B(P R-B)$. The ectopic endometrium in adenomyosis is rarely influenced by hormonal changes and has potent proliferative properties (37). In adenomyosis and endometriosis, the promoters of ER $\beta$ and PR-B are hypomethylated and hypermethylated, respectively $(67,102,103)$. ER- $\beta$ overexpression and the lack of PR-B expression may explain progesterone resistance (103). A similar expression pattern of ER- $\beta$ and PR-B was found in adenomyosis and endometriosis.

iv) $R X R A(R X R \alpha)$. RXRA is a member of the steroid and thyroid hormone receptor superfamily of transcriptional regulators. A decreased RXRA expression has been found in endometriotic stromal cells of patients with adenomyosis (16) and endometriosis (104).

v) OXTR. OXTR is upregulated in smooth muscle cells and epithelial cells in adenomyosis (105) and peritoneal endometriotic lesions and ovarian endometriotic cysts (106). OXTR overexpression may be responsible for increased uterine contractility and dysmenorrhea (107).

EMT (3 genes). EMT contributes pathologically to both adenomyosis and endometriosis, and this transition may be the fundamental event, such as increased cellular invasiveness and fibrogenesis (108). We explored key genes, including ANXA2, integrin linked kinase (ILK) and catenin beta1 (CTNNB1). 
ANXA2 may be a susceptibility gene that controls this transition.

i) ANXA2. ANXA2 acts as a tumor-associated protein and promotes cancer proliferation, invasion, EMT and metastasis (35). ANXA2 expression has been found to be upregulated (32) and downregulated $(33,34)$ in adenomyosis and endometriosis, respectively. E2 stimulates the expression of ANXA2 in adenomyotic endometrial cells and induces EMT and angiogenesis via the $\beta$-catenin/T-cell factor (Tcf) and HIF-1 $\alpha$ /VEGF-A signaling pathways (32). In addition, ANXA2 contributes to lung (109) and liver (110) injury and fibrosis, suggesting that ANXA2 may be involved in fibrotic process in adenomyosis occurring at the inner or the outer myometrium

ii) ILK. $\alpha \mathrm{V} \beta 3$-integrins promote tumor growth and metastasis by activating ILK via the Akt/mTOR and glycogen synthase kinase 3 beta (GSK-3 $\beta$ )/ $\beta$-catenin signaling pathways (111). ILK plays a role in intercellular adhesion and triggers the process of EMT, which plays a significant role in the pathogenesis of adenomyosis and endometriosis (112). ILK-induced EMT promotes the invasive phenotype in adenomyosis (112) and endometriosis (113).

iii) CTNNB1. The aberrant activation of the Wnt/ $\beta$-catenin pathway may be involved in the pathophysiology of adenomyosis $(114,115)$ and endometriosis $(116,117)$. E2 drives Wnt/ $\beta$-catenin triggered up-regulation of MMP-9 and VEGF (114,117).

Cell cycle regulation ( 3 genes). $\mathrm{p} 27^{\mathrm{kip} 1}$ and $\mathrm{p} 21^{\mathrm{CIP}}$ are key cell cycle regulators of endometriosis $(95,118)$. The dysregulation of the cell cycle control is one of the hallmarks of adenomyosis and endometriosis. Musashi RNA binding protein 1 (MSI1) and pluripotency markers [SRY-box transcription factor 2 (SOX2)/POU class 5 homeobox 1 (OCT4)] are overexpressed in adenomyosis; however, they are not able to distinguish adenomyosis from endometriosis.

i) MSI1 (also known as Musashi-1). MSI1, a stem cell marker, was identified as a regulator of cancer progression. MSI1 reduces the expression of $\mathrm{p} 21^{\mathrm{CIP}}$ and promotes cell proliferation and cell division. MSI1 expression has been shown to be increased in adenomyosis (119) and endometriosis (120).

ii) SOX2; and iii) OCT4 (also known as POU5F1). The transcription pluripotency factors, SOX2 and OCT4, have been shown to be overexpressed in adenomyosis and endometriosis (121).

Angiogenesis (1 gene). Ectopic endometriotic lesions produce multiple pro-angiogenic factors, including VEGF, angiopoietin (Ang)-1 and Ang-2, PDGF, IL-1 $\beta$, IL-6 and IL-8, TNF- $\alpha$, and TGF- $\beta$, Notch and HIF- $1 \alpha$ that were also upregulated in eutopic endometrium from patients with endometriosis in comparison with endometrium from healthy women (122). HIF-1 $\alpha$ represents a key regulator of angiogenesis. HIF-1 $\alpha$ expression has been shown to be increased in adenomyosis $(41,123)$ and endometriosis $(120)$.

i) $H I F-1 \alpha$. The ectopic endometrium of women with adenomyosis (41) and endometriosis (123) may contribute to an increased HIF-1 $\alpha$ expression and the stimulation of angiogenesis.

Oxidative damage (1 gene). Hemoglobin and iron originating from cyclic menstrual hemorrhage generate a wide range of reactive oxygen species (ROS) and hydroxy radicals, which also induce redox signaling (124). Oxidative stress and redox signaling may be implicated in the pathophysiology of adenomyosis and endometriosis.

i) GPX, glutathione peroxidase. The expression of the antioxidant protein, GPX, in adenomyosis has been shown $\mathrm{t}$ obe upregulated throughout the menstrual cycle $(13,125)$. The aberrant expression of GPX in the ectopic and eutopic endometrium also suggests a pathophysiological role in endometriosis (125). Thus, the expression level of GPX may be similar between two conditions.

\section{Mitochondrial dysfunction (1 gene)}

i) Superoxide dismutase 2 (SOD2; also known as $M n-S O D)$. Since mitochondrial DNA is sensitive to oxidative stress, ROS induces mitochondrial dysfunction. Adenomyosis and endometriosis may be associated with mitochondrial dysfunction, as reflected by enhanced inflammatory reaction and decreased ATP production $(13,126,127)$. ROS may induce mitochondrial antioxidant enzyme, superoxide dismutase (Mn-SOD) in ectopic endometrium of adenomyosis (128) and endometriosis (127).

\section{Prostaglandin biosynthesis (1 gene)}

i) Prostaglandin-endoperoxide synthase 2 (PTGS2). The expression of (PTGS2 (also known as prostaglandin $\mathrm{H}$ synthase) is high in the ectopic endometrium of patients with adenomyosis and endometriosis compared with eutopic endometrium, suggesting that ectopic lesions are capable of prostaglandin synthesis $(84,129)$.

\section{Conclusions and future considerations}

Despite the advent of numerous genetic techniques and molecular assessment, direct comparisons between adenomyosis and endometriosis have not been performed to date, at least to the best of our knowledge. In this review, we discuss the gene expression features and core regulatory genes with which to differentiate adenomyosis from endometriosis. Bioinformatics approaches were applied to analyze the high-throughput microarray datasets that were downloaded from NCBI-GEO. Patients with adenomyosis displayed both coincident $(91.2 \%)$ and distinct $(8.8 \%)$ gene expression profiles compared to patients with endometriosis. Through the comparison of the two conditions, we identified 274 (8.8\%) adenomyosis candidate genes that have little overlap with endometriosis. Among these, we selected 50 genes whose expression profiles have been published in a public repository (https://www.ncbi. nlm.nih.gov/pubmed/). Compared to endometriosis, adenomyosis exhibits an upregulation of IGF1, KISS1, NCAM1 and ANXA2, and a downregulation of OPN, VCAN and L-selectin ligand. The candidate genes specifically altered in adenomyosis may be related to the processes of invasion of the endometrial basalis into the myometrium (KISS1), cell survival and apoptosis (IGF1 and OPN), wound healing and scarring (NCAM1) and fibrosis (ANXA2).

First, several researchers have explored the proposed mechanisms of the pathogenesis of endometriosis. Recent biological studies have used large-scale datasets combined with bioinformatics to investigate global patterns of gene expression in a group of clinically heterogeneous disorders. The differential gene expression profiles were compared between ectopic and eutopic endometrial tissues of endometriosis via 
global genomics, transcriptomics and proteomics, coupled with bioinformatics and biostatistics $(6-11,130)$. Endometriosis is involved in pathways, such as hormonal regulation, proliferation, anti-apoptosis, cell cycle regulation, cytokines, chemokines, (pro)inflammatory and immune response, stress response and detoxification, metabolism, cell adhesion, motility, invasion and survival of endometriotic cells. These data have paid special attention to the role of oxidative stress, which may be implicated in the pathophysiology of endometriosis, causing a general inflammatory response $(131,132)$. The retrograde flow of menstrual blood followed by severe hemolysis occurs during the development of endometriosis, which results in high levels of free heme and iron $(131,132)$. These compounds lead to DNA damage, oxidatively modify lipids and proteins, and subsequently promote cell death, fibrosis and carcinogenesis (131). Iron may also alter genome stability through oxidative DNA damage and may have an impact on gene expression (132). The highly expressed genes in endometriosis mainly take part in the process of stress response, detoxification and anti-apoptosis $(131,132)$. Both the ectopic endometrium and eutopic endometrium in endometriosis exhibit anti-apoptotic activity (133). The aberrant expression of anti-apoptotic molecules, such as BCL2 may be involved in viability of ectopic endometrial cells by increasing cell proliferation and decreasing cell apoptosis $(38,55)$. Given that endometriotic cells live in harsh environmental conditions, an altered gene expression may result in enhanced anti-apoptosis in order to cope with oxidative stress.

Second, both adenomyosis and endometriosis are identical to their pathological and clinical features, although there are some differences with regard to the proposed pathogenesis. Adenomyosis results from the invagination of the endometrial basalis into the myometrium, while endometriosis originates from retrograde menstruation. The retrograde menstruation theory does not explain adenomyosis (134). Emerging evidence indicates that adenomyosis is a heterogeneous gynecologic condition and is subcategorized into at least 3 subtypes: Subtype I adenomyosis results from the invagination of the endometrial basalis into the myometrium; subtype II occurs in the uterine outer layer without affecting the inner structures; and subtype III adenomyosis results from metaplasia $(2,4)$. The identification of DEGs of each subtype will provide a basis for the understanding of the complex pathophysiology and etiology of adenomyosis and these genes may be used as biomarkers of the early development of adenomyosis. In addition, to explore the proposed mechanisms of the pathogenesis of adenomyosis, the differential gene expression profiles were compared between ectopic and eutopic endometrial tissues of adenomyosis. Compared with the eutopic endometrium of women with adenomyosis, the major pathways in terms of highly significant functional networks in ectopic lesions of adenomyosis included ER signaling (steroid hormone responsiveness); cell death and survival signaling (proliferation, angiogenesis and apoptosis); cell-to-cell signaling (cell adhesion, interaction, movement and invasion); signaling involved in extracellular matrix remodeling; EMT signaling; would healing, scarring and fibrosis; oxidative damage signaling (oxidative phosphorylation); inflammatory and immune response; mitochondrial dysfunction; prostaglandin biosynthesis; and altered lncRNA and miRNA expression profiles (12-14,36,37,41,67,70,84,125, 131,135-137). Herndon et al reported that comparative transcriptomic analysis identified 1,024 DEGs, 140 upregulated and 884 downregulated genes, in the endometrium of women with and without adenomyosis (13). The eutopic endometrium in patients with adenomyosis has undergone extensive gene expression changes (13). Not only the ectopic endometrium, but also the eutopic endometrium in patients with adenomyosis have fundamental abnormalities that may predispose to deep myometrial invasion, inflammation, would healing, scarring and then fibrosis, suggesting that these abnormalities may play an important role in the pathogenesis of adenomyosis.

Third, we discuss for the first time, to the best of our knowledge, the differential gene expression profiles of ectopic tissues from women with adenomyosis and those from women with endometriosis to explore core regulatory genes to differentiate adenomyosis from endometriosis. The present review provided a list of tissue-specific pathways that may be most suited for adenomyosis, which were enriched in the terms related to survival and apoptosis, immune and inflammatory response, invasion and extracellular matrix remodeling, adhesion and EMT (Table II). It was demonstrated that patients with adenomyosis displayed both coincident (91.2\%) and distinct $(8.8 \%)$ gene expression profiles compared to patients with endometriosis. One may raise the question whether the two conditions represent a continuum or separated clinical entities. The answer to the question we posed is that the patterns of gene expression profiling inferred from the two conditions are genetically similar. However, particularly noteworthy was that this study has revealed distinct molecular signatures specific for adenomyosis features. We found that $8.8 \%$ of the genes are considered to be adenomyosis candidate genes, leading to an improved knowledge of adenomyosis etiology. Vannuccini et al reported that adenomyosis and endometriosis share common genetic mutations, although recent studies offer a comprehensive landscape of different pathogenetic mechanisms, including sex steroid hormone receptors, inflammatory molecules, extracellular matrix degradation enzymes, growth factors and neuroangiogenic factors (138). A notable characteristic is that adenomyosis may be more invasive and survival benefit (increased expression of IGF1 and KISS1) than endometriosis; adenomyosis has an array of defensive mechanisms that can be adapted to cope with immune attack (decreased expression of OPN); and adenomyotic lesions show increased accumulation of ECM, leading ultimately to fibrosis, possibly through increased expression of ANXA2. Several genes and pathways that are specific to adenomyosis may provide potential therapeutic targets for adenomyosis in the future (135).

Finally, the results of this review are derived from high-throughput microarray genomic datasets submitted by the research community, which renders it difficult to draw firm conclusions with regard to the etiology of adenomyosis from existing evidence. Much of the published research datasets can be influenced by the diagnostic approach, age, menstrual cycle phase, the severity of the disease, intake of oral contraceptives, number of given births, tissue heterogeneity in lesions, the concomitant presence of endometriosis, or the difference in epigenetic modifications. Since both lesions consist of the different cell types (e.g., epithelial glandular cells, stromal cells, 
fibroblasts, myofibroblasts, mesenchymal cells, inflammatory cells, or immune cells), it is unclear which cells contribute to gene expression variability. Among the 274 adenomyosis candidate genes, we reviewed only 50 genes whose expression profiles are being published in a public repository. To date, the function of most of the candidate genes remain largely unknown. Notwithstanding these limitations, this review will help to elucidate the molecular mechanisms underlying the pathogenesis of adenomyosis.

In conclusion, herein, we present a comprehensive gene expression analysis of adenomyosis and endometriosis by using NCBI-GEO database to identify adenomyosis candidate genes and clarify the complex pathogenetic mechanisms.

\section{Summary}

Through eligible microarray data sets collected from NCBI-GEO, in this review, we present a large-scale survey for the identification of candidate functional networks and several key regulators to differentiate adenomyosis from endometriosis. The results of bioinformatics analysis revealed that adenomyosis patients displayed both coincident $(91.2 \%)$ and distinct $(8.8 \%)$ gene expression profiles compared to endometriosis patients. Both conditions share common pathways, but typical candidate genes are uniquely regulated in adenomyosis. According to the functional annotation of the DEG modules, the processes of invasion, immune response, cell survival, wound repair and fibrosis pathways are strongly associated with biological process terms in adenomyosis.

\section{Acknowledgements}

Not applicable.

\section{Funding}

No funding was received.

\section{Availability of data and materials}

All data generated or analyzed during this study are included in this published article.

\section{Authors' contributions}

SI and HN collected the datasets regarding the NCBI-GEO database and analyzed the databases to identify adenomyosis candidate genes. HK contributed to the conception, design and interpretation of this study. HK wrote the first draft. The final version of the manuscript has been read and approved by all authors.

\section{Ethics approval and consent to participate}

Not applicable.

\section{Patient consent for publication}

Not applicable.

\section{Competing interests}

The authors declare that they have no competing interests.

\section{References}

1. Harada T, Khine YM, Kaponis A, Nikellis T, Decavalas G and Taniguchi F: The impact of adenomyosis on Women's fertility. Obstet Gynecol Surv 71: 557-568, 2016.

2. García-Solares J, Donnez J, Donnez O and Dolmans MM: Pathogenesis of uterine adenomyosis: Invagination or metaplasia? Fertil Steril 109: 371-379, 2018.

3. Puente JM, Fabris A, Patel J, Patel A, Cerrillo M, Requena A and Garcia-Velasco JA: Adenomyosis in infertile women: Prevalence and the role of 3D ultrasound as a marker of severity of the disease. Reprod Biol Endocrinol 14: 60, 2016.

4. Kishi Y, Suginami H, Kuramori R, Yabuta M, Suginami R and Taniguchi F: Four subtypes of adenomyosis assessed by magnetic resonance imaging and their specification. Am J Obstet Gynecol 207: 114.e1-e7, 2012.

5. Vercellini P, Viganò P, Somigliana E and Fedele L: Endometriosis: Pathogenesis and treatment. Nat Rev Endocrinol 10: 261-275, 2014.

6. Crispi S, Piccolo MT, D'Avino A, Donizetti A, Viceconte R, Spyrou M, Calogero RA, Baldi A and Signorile PG: Transcriptional profiling of endometriosis tissues identifies genes related to organogenesis defects. J Cell Physiol 228: 1927-1934, 2013.

7. Abe W, Nasu K, Nakada C, Kawano Y, Moriyama M and Narahara H: miR-196b targets c-myc and Bcl-2 expression, inhibits proliferation and induces apoptosis in endometriotic stromal cells. Hum Reprod 28: 750-761, 2013.

8. Tamaresis JS, Irwin JC, Goldfien GA, Rabban JT, Burney RO, Nezhat C, DePaolo LV and Giudice LC: Molecular classification of endometriosis and disease stage using high-dimensional genomic data. Endocrinology 155: 4986-4999, 2014.

9. Saare M, Modhukur V, Suhorutshenko M, Rajashekar B, Rekker K, Sõritsa D, Karro H, Soplepmann P, Sõritsa A, Lindgren CM, et al: The influence of menstrual cycle and endometriosis on endometrial methylome. Clin Epigenetics 8: 2, 2016.

10. Zhao L, Gu C, Ye M, Zhang Z, Li L, Fan W and Meng Y: Integration analysis of microRNA and mRNA paired expression profiling identifies deregulated microRNA-transcription factor-gene regulatory networks in ovarian endometriosis. Reprod Biol Endocrinol 16: 4, 2018.

11. Yamagata Y, Nishino K, Takaki E, Sato S, Maekawa R, Nakai A and Sugino N: Genome-wide DNA methylation profiling in cultured eutopic and ectopic endometrial stromal cells. PLoS One 9: e83612, 2014.

12. Zhou C, Zhang T, Liu F, Zhou J, Ni X, Huo R and Shi Z: The differential expression of mRNAs and long noncoding RNAs between ectopic and eutopic endometria provides new insights into adenomyosis. Mol Biosyst 12: 362-370, 2016.

13. Herndon CN, Aghajanova L, Balayan S, Erikson D, Barragan F, Goldfien G, Vo KC, Hawkins S and Giudice LC: Global transcriptome abnormalities of the eutopic endometrium from women with adenomyosis. Reprod Sci 23: 1289-1303, 2016.

14. Jiang JF, Sun AJ, Xue W, Deng Y and Wang YF: Aberrantly expressed long noncoding RNAs in the eutopic endometria of patients with uterine adenomyosis. Eur J Obstet Gynecol Reprod Biol 199: 32-37, 2016.

15. Tang Q, Wang Q, Zhang Q, Lin SY, Zhu Y, Yang X and Guo AY: Gene expression, regulation of DEN and HBx induced HCC mice models and comparisons of tumor, para-tumor and normal tissues. BMC Cancer 17: 862, 2017.

16. Levy M, Mittal K, Chiriboga L, Zhang X, Yee H and Wei JJ: Differential expression of selected gene products in uterine leiomyomata and adenomyosis. Fertil Steril 88: 220-223, 2007.

17. Konopka B, Skasko E, Kluska A, Goluda M, Janiec-Jankowska A, Paszko $Z$ and Ujec M: Changes in the concentrations of receptors of insulin-like growth factor-I, epithelial growth factor, oestrogens and progestagens in adenomyosis foci, endometrium and myometrium of women during menstrual cycle. Eur J Gynaecol Oncol 19: 93-97, 1998.

18. Chang SY and Ho YS: Immunohistochemical analysis of insulin-like growth factor I, insulin-like growth factor I receptor and insulin-like growth factor II in endometriotic tissue and endometrium. Acta Obstet Gynecol Scand 76: 112-117, 1997. 
19. Kim JG, Suh CS, Kim SH, Choi YM, Moon SY and Lee JY: Insulin-like growth factors (IGFs), IGF-binding proteins (IGFBPs), and IGFBP-3 protease activity in the peritoneal fluid of patients with and without endometriosis. Fertil Steril 73: 996-1000, 2000

20. Streuli I, Santulli P, Chouzenoux S, Chapron C and Batteux F: Serum osteopontin levels are decreased in focal adenomyosis. Reprod Sci 24: 773-782, 2017.

21. Xiao Y, Li T, Xia E, Yang X, Sun X and Zhou Y: Expression of integrin $\beta 3$ and osteopontin in the eutopic endometrium of adenomyosis during the implantation window. Eur J Obstet Gynecol Reprod Biol 170: 419-422, 2013.

22. Cho S, Ahn YS, Choi YS, Seo SK, Nam A, Kim HY, Kim JH, Park KH, Cho DJ and Lee BS: Endometrial osteopontin mRNA expression and plasma osteopontin levels are increased in patients with endometriosis. Am J Reprod Immunol 61: 286-293, 2009.

23. Kolioulis I, Zafrakas M, Grimbizis G, Miliaras D, Timologou A, Bontis JN and Tarlatzis BC: Immunohistochemical expression pattern of metastasis suppressor KISS-1 protein in adenomyosis lesions and normal endometrium. Eur J Obstet Gynecol Reprod Biol 210: 64-68, 2017.

24. Ji K, Ye L, Mason MD and Jiang WG: The Kiss-1/Kiss-1R complex as a negative regulator of cell motility and cancer metastasis (Review). Int J Mol Med 32: 747-754, 2013.

25. Timologou A, Zafrakas M, Grimbizis G, Miliaras D, Kotronis K, Stamatopoulos P and Tarlatzis BC: Immunohistochemical expression pattern of metastasis suppressors KAI1 and KISS1 in endometriosis and normal endometrium. Eur J Obstet Gynecol Reprod Biol 199: 110-115, 2016.

26. Hussain MA, Song WJ and Wolfe A: There is Kisspeptin- and then there is kisspeptin. Trends Endocrinol Metab 26: 564-572, 2015.

27. Fratangelo F, Carriero MV and Motti ML: Controversial role of Kisspeptins/KiSS-1R signaling system in tumor development. Front Endocrinol (Lausanne) 9: 192, 2018.

28. Wang F, Shi X, Qin X, Wen Z, Zhao X and Li C: Expression of CD56 in patients with adenomyosis and its correlation with dysmenorrhea. Eur J Obstet Gynecol Reprod Biol 194: 101-105, 2015.

29. Oosterlynck DJ, Meuleman C, Lacquet FA, Waer M and Koninckx PR: Flow cytometry analysis of lymphocyte subpopulations in peritoneal fluid of women with endometriosis. Am J Reprod Immunol 31: 25-31, 1994.

30. Tani H, Sato Y, Ueda M, Miyazaki Y, Suginami K, Horie A, Konishi I and Shinomura T: Role of Versican in the pathogenesis of peritoneal endometriosis. J Clin Endocrinol Metab 101: 4349-4356, 2016

31. Lai TH, Chang FW, Lin JJ and Ling QD: Endometrial L-selectin ligand is downregulated in the mid-secretory phase during the menstrual cycle in women with adenomyosis. Taiwan J Obstet Gynecol 57: 507-516, 2018.

32. Zhou S, Yi T, Liu R, Bian C, Qi X, He X, Wang K, Li J, Zhao X, Huang $\mathrm{C}$ and Wei Y: Proteomics identification of annexin A2 as a key mediator in the metastasis and proangiogenesis of endometrial cells in human adenomyosis. Mol Cell Proteomics 11: M112.017988, 2012.

33. Wu MH, Chuang PC, Lin YJ and Tsai SJ: Suppression of annexin A2 by prostaglandin $E_{2}$ impairs phagocytic ability of peritoneal macrophages in women with endometriosis. Hum Reprod 28 : 1045-1053, 2013

34. Fowler PA, Tattum J, Bhattacharya S, Klonisch T, Hombach-Klonisch S, Gazvani R, Lea RG, Miller I, Simpson WG and Cash P: An investigation of the effects of endometriosis on the proteome of human eutopic endometrium: A heterogeneous tissue with a complex disease. Proteomics 7: 130-142, 2007.

35. Chen CY, Lin YS, Chen CH and Chen YJ: Annexin A2-mediated cancer progression and therapeutic resistance in nasopharyngeal carcinoma. J Biomed Sci 25: 30, 2018.

36. Yang JH, Wu MY, Chen CD, Chen MJ, Yang YS and Ho HN: Altered apoptosis and proliferation in endometrial stromal cells of women with adenomyosis. Hum Reprod 22: 945-952, 2007.

37. Matsumoto Y, Iwasaka T, Yamasaki F and Sugimori H: Apoptosis and $\mathrm{Ki}-67$ expression in adenomyotic lesions and in the corresponding eutopic endometrium. Obstet Gynecol 94: 71-77, 1999.

38. Jones RK, Searle RF and Bulmer JN: Apoptosis and bcl-2 expression in normal human endometrium, endometriosis and adenomyosis. Hum Reprod 13: 3496-3502, 1998.

39. $\mathrm{Hu} \mathrm{H}, \mathrm{Li} \mathrm{H}$ and $\mathrm{He} \mathrm{Y}$ : MicroRNA-17 downregulates expression of the PTEN gene to promote the occurrence and development of adenomyosis. Exp Ther Med 14: 3805-3811, 2017.
40. Lai TH, Wu PH and Wu WB: Involvement of NADPH oxidase and NF- $\kappa \mathrm{B}$ activation in CXCL1 induction by vascular endothelial growth factor in human endometrial epithelial cells of patients with adenomyosis. J Reprod Immunol 118: 61-69, 2016.

41. Goteri G, Lucarini G, Montik N, Zizzi A, Stramazzotti D, Fabris G, Tranquilli AL and Ciavattini A: Expression of vascular endothelial growth factor (VEGF), hypoxia inducible factor-1alpha (HIF-1alpha), and microvessel density in endometrial tissue in women with adenomyosis. Int J Gynecol Pathol 28: $157-163,2009$

42. Huang TS, Chen YJ, Chou TY, Chen CY, Li HY, Huang BS, Tsai HW, Lan HY, Chang CH, Twu NF, et al: Oestrogen-induced angiogenesis promotes adenomyosis by activating the Slug-VEGF axis in endometrial epithelial cells. J Cell Mol Med 18: 1358-1371, 2014.

43. Khan KN, Kitajima M, Hiraki K, Fujishita A, Nakashima M and Masuzaki H: Involvement of hepatocyte growth factor-induced epithelial-mesenchymal transition in human adenomyosis. Biol Reprod 92: 35, 2015.

44. Yerlikaya G, Balendran S, Pröstling K, Reischer T, Birner P, Wenzl R, Kuessel L, Streubel B and Husslein H: Comprehensive study of angiogenic factors in women with endometriosis compared to women without endometriosis. Eur J Obstet Gynecol Reprod Biol 204: 88-98, 2016.

45. Fukaya T, Sugawara J, Yoshida H, Murakami T and Yajima A: Intercellular adhesion molecule-1 and hepatocyte growth factor in human endometriosis: Original investigation and a review of literature. Gynecol Obstet Invest 47 (Suppl 1): S11-S17, 1999.

46. Carrarelli P, Yen CF, Funghi L, Arcuri F, Tosti C, Bifulco G, Luddi A, Lee CL and Petraglia F: Expression of inflammatory and neurogenic mediators in adenomyosis. Reprod Sci 24: 369-375, 2017

47. Li Y, Zou S, Xia X and Zhang S: Human adenomyosis endometrium stromal cells secreting more nerve growth factor: Impact and effect. Reprod Sci 22: 1073-1082, 2015.

48. Kajitani T, Maruyama T, Asada H, Uchida H, Oda H, Uchida S, Miyazaki K, Arase T, Ono M and Yoshimura Y: Possible involvement of nerve growth factor in dysmenorrhea and dyspareunia associated with endometriosis. Endocr J 60: 1155-1164, 2013.

49. Lee SR, Kim SH, Lee YJ, Hong SH, Chae HD, Kim CH, Kang BM and Choi YM: Expression of epidermal growth factor, fibroblast growth factor-2, and platelet-derived growth factor-A in the eutopic endometrium of women with endometriosis. J Obstet Gynaecol Res 33: 242-247, 2007.

50. Yang RQ, Teng H, Xu XH, Liu SY, Wang YH, Guo FJ and Liu XJ: Microarray analysis of microRNA deregulation and angiogenesis-related proteins in endometriosis. Genet Mol Res: Jun 3, 2016 (Epub ahead of print). doi: 10.4238/gmr.15027826.

51. Propst AM, Quade BJ, Gargiulo AR, Nowak RA and Stewart EA: Adenomyosis demonstrates increased expression of the basic fibroblast growth factor receptor/ligand system compared with autologous endometrium. Menopause 8: 368-371, 2001.

52. Guo Q, Zhang H, Zhao X, Fu Y, Zhang J and Li M: Loss of expressions of Dusp6, Sprouty4, and Sef, negative regulators of FGF2/ERK1/2 signaling, in the endometrium of women with adenomyosis. Int J Gynecol Pathol 33: 288-297, 2014.

53. Streuli I, Santulli P, Chouzenoux S, Chapron C and Batteux F: Activation of the MAPK/ERK cell-signaling pathway in uterine smooth muscle cells of women with Adenomyosis. Reprod Sci 22: 1549-1560, 2015.

54. Guo J, Gao J, Yu X, Luo H, Xiong X and Huang O: Expression of DJ-1 and mTOR in eutopic and ectopic endometria of patients with endometriosis and adenomyosis. Gynecol Obstet Invest 79: 195-200, 2015.

55. Goumenou A, Panayiotides I, Matalliotakis I, Vlachonikolis I, Tzardi $\mathrm{M}$ and Koumantakis E: Bcl-2 and Bax expression in human endometriotic and adenomyotic tissues. Eur J Obstet Gynecol Reprod Biol 99: 256-260, 2001.

56. Preya UH, Woo JH, Choi YS and Choi JH: HNF1 $\beta$ protects endometriotic cells against apoptotic cell death by upregulating the expression of anti-apoptotic genes. Biol Reprod: Jun 18, 2019 (Epub ahead of print). doi: 10.1093/biolre/ioz127.

57. Li J, Yanyan M, Mu L, Chen X and Zheng W: The expression of Bcl-2 in adenomyosis and its effect on proliferation, migration, and apoptosis of endometrial stromal cells. Pathol Res Pract 215: $152477,2019$.

58. Ren Y, Mu L, Ding X and Zheng W: Decreased expression of Beclin 1 in eutopic endometrium of women with adenomyosis. Arch Gynecol Obstet 282: 401-406, 2010. 
59. Zhang L, Liu Y, Xu Y, Wu H, Wei Z and Cao Y: The expression of the autophagy gene beclin-1 mRNA and protein in ectopic and eutopic endometrium of patients with endometriosis. Int J Fertil Steril 8: 429-436, 2015.

60. Liu Y, Tan X, Wang Z, Li Y, Gao M, Li Y, Fang Z, Sun Y, Zhang L, Wang $X$ and Wei $Z$ : Down-regulation of tumor suppressor PDCD4 expression in endometrium of adenomyosis patients. Curr Res Transl Med 64: 123-128, 2016.

61. Li Y, Wang X, Wang X, Wan L, Liu Y, Shi Y, Zhang L, Fang Z and Wei Z: PDCD4 suppresses proliferation, migration, and invasion of endometrial cells by inhibiting autophagy and NF-кB/MMP2/MMP9 signal pathway. Biol Reprod 99: 360-372, 2018.

62. Maia H Jr, Maltez A, Studart E, Athayde C and Coutinho EM: Effect of menstrual cycle and hormonal treatment on ki-67 and bcl-2 expression and adenomyosis. Gynecol Endocrinol 20: 127-131, 2005.

63. Thiruchelvam U, Wingfield $\mathrm{M}$ and O'Farrelly C: Natural killer cells: Key players in endometriosis. Am J Reprod Immunol 74 291-301, 2015.

64. Yang JH, Chen MJ, Chen HF, Lee TH, Ho HN and Yang YS: Decreased expression of killer cell inhibitory receptors on natural killer cells in eutopic endometrium in women with adenomyosis. Hum Reprod 19: 1974-1978, 2004

65. Monsanto SP, Edwards AK, Zhou J, Nagarkatti P, Nagarkatti M, Young SL, Lessey BA and Tayade C: Surgical removal of endometriotic lesions alters local and systemic proinflammatory cytokines in endometriosis patients. Fertil Steril 105: 968-977.e5, 2016.

66. Propst AM, Quade BJ, Nowak RA and Stewart EA: Granulocyte macrophage colony-stimulating factor in adenomyosis and autologous endometrium. J Soc Gynecol Investig 9: 93-97, 2002.

67. Nie J,Lu Y,Liu X and Guo SW: Immunoreactivity of progesterone receptor isoform $\mathrm{B}$, nuclear factor kappaB, and IkappaBalpha in adenomyosis. Fertil Steril 92: 886-889, 2009.

68. Liu X, Shen M, Qi Q, Zhang H and Guo SW: Corroborating evidence for platelet-induced epithelial-mesenchymal transition and fibroblast-to-myofibroblast transdifferentiation in the development of adenomyosis. Hum Reprod 31: 734-749, 2016.

69. Shen M, Liu X, Zhang H and Guo SW: Transforming growth factor $\beta 1$ signaling coincides with epithelial-mesenchymal transition and fibroblast-to-myofibroblast transdifferentiation in the development of adenomyosis in mice. Hum Reprod 31: 355-369, 2016.

70. An M, Li D, Yuan M, Li Q, Zhang L and Wang G: Interaction of macrophages and endometrial cells induces epithelial-mesenchymal transition-like processes in adenomyosis. Biol Reprod 96 46-57, 2017.

71. Young VJ, Ahmad SF, Duncan WC and Horne AW: The role of TGF- $\beta$ in the pathophysiology of peritoneal endometriosis. Hum Reprod Update 23: 548-559, 2017.

72. Yen CF, Liao SK, Huang SJ, Tabak S, Arcuri F, Lee CL, Arici A, Petraglia F, Wang HS and Kayisli UA: Decreased endometrial expression of leukemia inhibitory factor receptor disrupts the STAT3 signaling in adenomyosis during the implantation window. Reprod Sci 24: 1176-1186, 2017.

73. Dimitriadis E, Stoikos C, Stafford-Bell M, Clark I, Paiva P, Kovacs G and Salamonsen LA: Interleukin-11, IL-11 receptoralpha and leukemia inhibitory factor are dysregulated in endometrium of infertile women with endometriosis during the implantation window. J Reprod Immunol 69: 53-64, 2006.

74. Jiang C, Liu C, Guo J, Chen L, Luo N, Qu X, Yang W, Ren Q and Cheng Z: The Expression of Toll-like receptors in eutopic and ectopic endometrium and its implication in the inflammatory pathogenesis of adenomyosis. Sci Rep 7: 7365, 2017.

75. Khan KN, Kitajima M, Fujishita A, Nakashima $M$ and Masuzaki H: Toll-like receptor system and endometriosis. J Obstet Gynaecol Res 39: 1281-1292, 2013.

76. Sikora J, Mielczarek-Palacz A and Kondera-Anasz Z: Association of the precursor of interleukin- $1 \beta$ and peritoneal inflammation-role in pathogenesis of endometriosis. J Clin Lab Anal 30: 831-837, 2016

77. Wang J, Huang C, Jiang R, Du Y, Zhou J, Jiang Y, Yan Q, Xing J, Hou X, Zhou J, et al: Decreased endometrial IL-10 impairs endometrial receptivity by downregulating HOXA10 expression in women with adenomyosis. Biomed Res Int 2018: 2549789, 2018.

78. Wang F, Li H, Yang Z, Du X, Cui M and Wen Z: Expression of interleukin-10 in patients with adenomyosis. Fertil Steril 91: $1681-1685,2009$.
79. Szamatowicz J,Laudański P, Tomaszewska I and Szamatowicz M: Chemokine growth-regulated-alpha: A possible role in the pathogenesis of endometriosis. Gynecol Endocrinol 16: 137-141, 2002.

80. Takamura M, Osuga Y, Izumi G, Yoshino O, Koga K, Saito A, Hirata T, Hirota Y, Harada M, Hasegawa A and Taketani Y: Interleukin-17A is present in neutrophils in endometrioma and stimulates the secretion of growth-regulated oncogene- $\alpha$ (Gro- $\alpha$ ) from endometrioma stromal cells. Fertil Steril 98: 1218-1224.e1-e2, 2012.

81. Yu X, Ren H, Liu T, Yong M and Zhong H: Expression and significance of ER $\beta$ and TrkB in endometriosis. Clin Exp Obstet Gynecol 43: 75-81, 2016.

82. Huang Y, Zheng W, Mu L, Ren Y, Chen X and Liu F: Expression of tyrosine kinase receptor B in eutopic endometrium of women with adenomyosis. Arch Gynecol Obstet 283: 775-780, 2011.

83. Tokyol C, Aktepe F, Dilek FH, Sahin O and Arioz DT: Expression of cyclooxygenase-2 and matrix metalloproteinase-2 in adenomyosis and endometrial polyps and its correlation with angiogenesis. Int J Gynecol Pathol 28: 148-156, 2009.

84. Chen YJ, Li HY, Chang YL, Yuan CC, Tai LK, Lu KH, Chang $\mathrm{CM}$ and Chiou $\mathrm{SH}$ : Suppression of migratory/invasive ability and induction of apoptosis in adenomyosis-derived mesenchymal stem cells by cyclooxygenase- 2 inhibitors. Fertil Steril 94: 1972-1979.e1-e4, 2010.

85. Fagotti A, Ferrandina G, Fanfani F, Legge F, Lauriola L, Gessi M, Castelli P, Barbieri F, Minelli L and Scambia G: Analysis of cyclooxygenase-2 (COX-2) expression in different sites of endometriosis and correlation with clinico-pathological parameters. Hum Reprod 19: 393-397, 2004.

86. Huang F, Cao J, Liu Q, Zou Y, Li H and Yin T: MAPK/ERK signal pathway involved expression of COX-2 and VEGF by IL-1 $\beta$ induced in human endometriosis stromal cells in vitro. Int J Clin Exp Pathol 6: 2129-2136, 2013.

87. Li T, Li YG and Pu DM: Matrix metalloproteinase-2 and -9 expression correlated with angiogenesis in human adenomyosis. Gynecol Obstet Invest 62: 229-235, 2006.

88. Szymanowski K, Mikołajczyk M, Wirstlein $\mathrm{P}$ and Dera-Szymanowska A: Matrix metalloproteinase-2 (MMP-2), MMP-9, tissue inhibitor of matrix metalloproteinases (TIMP-1) and transforming growth factor- $\beta 2$ (TGF- $\beta 2$ ) expression in eutopic endometrium of women with peritoneal endometriosis. Ann Agric Environ Med 23: 649-653, 2016.

89. Shan K, Lian-Fu Z, Hui D, Wei G, Na W, Xia J and Yan L: Polymorphisms in the promoter regions of the matrix metalloproteinases-7, -9 and the risk of endometriosis and adenomyosis in China. Mol Hum Reprod 12: 35-39, 2006.

90. Ohara R, Michikami H, Nakamura Y, Sakata A, Sakashita S, Satomi K, Shiba-Ishii A, Kano J, Yoshikawa H and Noguchi M: Moesin overexpression is a unique biomarker of adenomyosis. Pathol Int 64: 115-122, 2014.

91. Ametzazurra A, Matorras R, García-Velasco JA, Prieto B, Simón L, Martínez A and Nagore D: Endometrial fluid is a specific and non-invasive biological sample for protein biomarker identification in endometriosis. Hum Reprod 24: 954-965, 2009

92. Zheng D, Duan H, Wang S, Xu Q, Gan L, Li J and Dong Q: FAK regulates epithelial-mesenchymal transition in adenomyosis. Mol Med Rep 18: 5461-5472, 2018.

93. Mu L, Zheng W, Wang L, Chen XJ, Zhang X and Yang JH: Alteration of focal adhesion kinase expression in eutopic endometrium of women with endometriosis. Fertil Steril 89: 529-537, 2008.

94. Ruiz LA, Báez-Vega PM, Ruiz A, Peterse DP, Monteiro JB, Bracero N, Beauchamp P, Fazleabas AT and Flores I: Dysregulation of Lysyl oxidase expression in lesions and endometrium of women with endometriosis. Reprod Sci 22: 1496-1508, 2015.

95. Zhang D, Li Y, Tian J, Zhang H and Wang S: MiR-202 promotes endometriosis by regulating SOX6 expression. Int J Clin Exp Med 8: 17757-1764, 2015

96. Shen F, Liu X, Geng JG and Guo SW: Increased immunoreactivity to SLIT/ROBO1 in ovarian endometriomas: A likely constituent biomarker for recurrence. Am J Pathol 175: 479-488, 2009.

97. Nie J, Liu X, Zheng Y, Geng JG and Guo SW: Increased immunoreactivity to SLIT/ROBO1 and its correlation with severity of dysmenorrhea in adenomyosis. Fertil Steril 95: 1164-1167, 2011.

98. Roy R, Dagher A, Butterfield C and Moses MA: ADAM12 is a novel regulator of tumor angiogenesis via STAT3 signaling. Mol Cancer Res 15: 1608-1622, 2017. 
99. Miller MA, Moss ML, Powell G, Petrovich R, Edwards L, Meyer AS, Griffith LG and Lauffenburger DA: Targeting autocrine HB-EGF signaling with specific ADAM12 inhibition using recombinant ADAM12 prodomain. Sci Rep 5: 15150, 2015 .

100. Koike N, Higashiura Y, Akasaka J, Uekuri C, Ito F and Kobayashi H: Epigenetic dysregulation of endometriosis susceptibility genes (Review). Mol Med Rep 12: 1611-1616, 2015.

101. Han SJ, Jung SY, Wu SP, Hawkins SM, Park MJ, Kyo S, Qin J, Lydon JP, Tsai SY, Tsai MJ, et al: Estrogen receptor $\beta$ modulates apoptosis complexes and the inflammasome to drive the pathogenesis of endometriosis. Cell 163: 960-974, 2015.

102. Jichan N, Xishi L and Guo SW: Promoter hypermethylation of progesterone receptor isoform $\mathrm{B}$ (PR-B) in adenomyosis and its rectification by a histone deacetylase inhibitor and a demethylation agent. Reprod Sci 17: 995-1005, 2010.

103. Bulun SE, Cheng YH, Pavone ME, Xue Q, Attar E Trukhacheva E, Tokunaga $\mathrm{H}$, Utsunomiya $\mathrm{H}$, Yin $\mathrm{P}$, Luo X, et al: Estrogen receptor-beta, estrogen receptor-alpha, and progesterone resistance in endometriosis. Semin Reprod Med 28: $36-43,2010$

104. Pavone ME, Dyson M, Reirstad S, Pearson E, Ishikawa H, Cheng YH and Bulun SE: Endometriosis expresses a molecular pattern consistent with decreased retinoid uptake, metabolism and action. Hum Reprod 26: 2157-2164, 2011.

105. Zhang Y, Yu P, Sun F, Li TC, Cheng JM and Duan H: Expression of oxytocin receptors in the uterine junctional zone in women with adenomyosis. Acta Obstet Gynecol Scand 94: 412-418, 2015

106. Mechsner S, Bartley J, Loddenkemper C, Salomon DS Starzinski-Powitz A and Ebert AD: Oxytocin receptor expression in smooth muscle cells of peritoneal endometriotic lesions and ovarian endometriotic cysts. Fertil Steril 83 (Suppl 1): S1220-S1231, 2005

107. Guo SW, Mao X, Ma Q and Liu X: Dysmenorrhea and its severity are associated with increased uterine contractility and overexpression of oxytocin receptor (OTR) in women with symptomatic adenomyosis. Fertil Steril 99: 231-240, 2013.

108. Matsuzaki S and Darcha C: Involvement of the Wnt/ $\beta$-catenin signaling pathway in the cellular and molecular mechanisms of fibrosis in endometriosis. PLoS One 8: e76808, 2013.

109. Schuliga M, Jaffar J, Berhan A, Langenbach S, Harris T, Waters D, Lee PVS, Grainge C, Westall G, Knight D and Stewart AG: Annexin A2 contributes to lung injury and fibrosis by augmenting factor Xa fibrogenic activity. Am J Physiol Lung Cell Mol Physiol 312: L772-L782, 2017.

110. Kolgelier S, Demir NA, Inkaya AC, Sumer S, Ozcimen S, Demir LS, Pehlivan FS, Arslan M and Arpaci A: Serum levels of Annexin A2 as a candidate biomarker for hepatic fibrosis in patients with chronic hepatitis B. Hepat Mon 15: e30655, 2015.

111. Hannigan G, Troussard AA and Dedhar S: Integrin-linked kinase: A cancer therapeutic target unique among its ILK. Nat Rev Cancer 5: 51-63, 2005.

112. Zhou W, Peng Z, Zhang C, Liu S and Zhang Y: ILK-induced epithelial-mesenchymal transition promotes the invasive phenotype in adenomyosis. Biochem Biophys Res Commun 497: 950-956, 2018.

113. Zheng QM, Chen XY, Bao QF, Yu J and Chen LH: ILK enhances migration and invasion abilities of human endometrial stromal cells by facilitating the epithelial-mesenchymal transition. Gynecol Endocrinol 34: 1091-1096, 2018.

114. Oh SJ, Shin JH, Kim TH, Lee HS, Yoo JY, Ahn JY, Broaddus RR, Taketo MM, Lydon JP, Leach RE, et al: $\beta$-Catenin activation contributes to the pathogenesis of adenomyosis through epithelial-mesenchymal transition. J Pathol 231: 210-222, 2013.

115. Chen YJ, Li HY, Huang CH, Twu NF, Yen MS, Wang PH, Chou TY, Liu YN, Chao KC and Yang MH: Oestrogen-induced epithelial-mesenchymal transition of endometrial epithelial cells contributes to the development of adenomyosis. J Pathol 222: 261-270, 2010

116. Yang YM and Yang WX: Epithelial-to-mesenchymal transition in the development of endometriosis. Oncotarget 8: 41679-41689, 2017.

117. Matsuzaki S, Botchorishvili R, Pouly JL and Canis M: Targeting the Wnt/ $\beta$-catenin pathway in endometriosis: A potentially effective approach for treatment and prevention. Mol Cell Ther 2: 36, 2014.

118. Gonçalves GA: $27^{\mathrm{kipl}}$ as a key regulator of endometriosis. Eur J Obstet Gynecol Reprod Biol 221: 1-4, 2018.
119. Kozachenko IF, Dzhamalutdinova KM, Faizullina NM and Shchegolev AI: Immunohistochemical parameters of Musashi-1 in nodular and diffuse adenomyosis. Bull Exp Biol Med 163 506-509, 2017.

120. Götte M, Wolf M, Staebler A, Buchweitz O, Kelsch R, Schüring AN and Kiesel L: Increased expression of the adult stem cell marker Musashi-1 in endometriosis and endometrial carcinoma. J Pathol 215: 317-329, 2008

121. Song Y, Xiao L, Fu J, Huang W, Wang Q, Zhang X and Yang S: Increased expression of the pluripotency markers sex-determining region Y-box 2 and Nanog homeobox in ovarian endometriosis. Reprod Biol Endocrinol 12: 42, 2014.

122. Djokovic D and Calhaz-Jorge C: Angiogenesis as a therapeutic target in endometriosis. Acta Med Port 27: 489-497, 2014.

123. Liu H, Zhang Z, Xiong W, Zhang L, Xiong Y, Li N, He H, Du Y and Liu Y: Hypoxia-inducible factor- $1 \alpha$ promotes endometrial stromal cells migration and invasion by upregulating autophagy in endometriosis. Reproduction 153: 809-820, 2017.

124. Scutiero G, Iannone P, Bernardi G, Bonaccorsi G, Spadaro S, Volta CA, Greco P and Nappi L: Oxidative stress and endometriosis: A systematic review of the literature. Oxid Med Cell Longev 2017: 7265238, 2017

125. Ota $\mathrm{H}$, Igarashi S, Kato $\mathrm{N}$ and Tanaka T: Aberrant expression of glutathione peroxidase in eutopic and ectopic endometrium in endometriosis and adenomyosis. Fertil Steril 74: 313-318, 2000

126. Hsu AL, Townsend PM, Oehninger S and Castora FJ: Endometriosis may be associated with mitochondrial dysfunction in cumulus cells from subjects undergoing in vitro fertilization-intracytoplasmic sperm injection, as reflected by decreased adenosine triphosphate production. Fertil Steril 103 347-352.e1, 2015.

127. Chen C, Zhou Y, Hu C, Wang Y, Yan Z, Li Z and Wu R: Mitochondria and oxidative stress in ovarian endometriosis Free Radic Biol Med 136: 22-34, 2019.

128. Ishikawa M, Nakata T, Yaginuma Y, Nishiwaki K, Goishi K and Saitoh S: Expression of superoxide dismutase (SOD) in adenomyosis. Am J Obstet Gynecol 169: 730-734, 1993.

129. Van Voorhis BJ, Huettner PC, Clark MR and Hill JA: Immunohistochemical localization of prostaglandin $\mathrm{H}$ synthase in the female reproductive tract and endometriosis. Am J Obstet Gynecol 163: 57-62, 1990.

130. Kobayashi H, Uekuri $\mathrm{C}$ and Shigetomi $\mathrm{H}$ : Towards an understanding of the molecular mechanism of endometriosis Unbalancing epithelial-stromal genetic conflict. Gynecol Endocrinol 30: 7-15, 2014

131. Kobayashi H, Yamada Y, Kanayama S, Furukawa N, Noguchi T, Haruta S, Yoshida S, Sakata M, Sado T and Oi H: The role of iron in the pathogenesis of endometriosis. Gynecol Endocrinol 25 39-52, 2009.

132. Akasaka J, Uekuri C, Shigetomi H, Koike M and Kobayashi H: Hepatocyte nuclear factor (HNF)-1 $\beta$ and its physiological importance in endometriosis. Biomed Rep 1: 13-17, 2013.

133. Meresman GF, Vighi S, Buquet RA, Contreras-Ortiz O, Tesone M and Rumi LS: Apoptosis and expression of Bcl-2 and Bax in eutopic endometrium from women with endometriosis. Fertil Steril 74: 760-766, 2000.

134. Benagiano G, Brosens I and Habiba M: Structural and molecular features of the endomyometrium in endometriosis and adenomyosis. Hum Reprod Update 20: 386-402, 2014.

135. Xiaoyu L, Weiyuan Z, Ping J, Anxia W and Liane Z: Comparative serum proteomic analysis of adenomyosis using the isobaric tags for relative and absolute quantitation technique. Fertil Steril 100: 505-510,2013.

136. Hever A, Roth RB, Hevezi PA, Lee J, Willhite D, White EC, Marin EM, Herrera R, Acosta HM, Acosta AJ and Zlotnik A: Molecular characterization of human adenomyosis. Mol Hum Reprod 12: 737-748, 2006

137. Kobayashi H, Iwai K, Niiro E, Morioka S and Yamada Y: Fetal programming theory: Implication for the understanding of endometriosis. Hum Immunol 75: 208-217, 2014

138. Vannuccini S, Tosti C, Carmona F, Huang SJ, Chapron C, Guo SW and Petraglia F: Pathogenesis of adenomyosis: An update on molecular mechanisms. Reprod Biomed Online 35: 592-601, 2017.

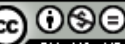

This work is licensed under a Creative Common Attribution-NonCommercial-NoDerivatives 4.0 International (CC BY-NC-ND 4.0) License. 